\title{
Medical Considerations Relating to the Oral Health
}

\author{
Hassan H Koshak* \\ Department and Dental Educator, Ministry of Interior Security Forces Medical Services, Kingdom of Saudi Arabia
}

Submission: March 13, 2018; Published: March 23, 2018

*Corresponding author: Hassan H Koshak, Head of the Dental Department and Dental Educator, Director of Academic and Education Affairs at Comprehensive Specialized Polyclinic, Ministry of Interior Security Forces Medical Services, Jeddah, Kingdom of Saudi Arabia, Tel: 966555507035; Email: Koshak.hh@gmail.com

Abstract

The human body is comprised of complex systems, which are interconnected with each other. Because of the way, the human body is made; one organ of the body can have an impact on other organs of it. Oral health affects people physically and psychologically and influences how they grow, enjoy life, look, speak, chew, taste food and socialize, as well as their feelings of social well-being. The oral hygiene measures related to professional level, level of education, and periodontal maintenance. Some studies report that oral health has an impact on food choice and on the intake of key nutrients, causing various nutritional problems. Recent researches on oral and general health have shown a link between the two. With more than $90 \%$ of systemic diseases having oral symptoms. These symptoms can include swollen gums, sores, ulcers, dry mouth and more. The following diseases are an example of a systemic disease which has symptoms expressed in the mouth like diabetes, leukaemia, oral cancer, pancreatic cancer, heart disease and kidney disease.

Research has also shown that poor dental hygiene and gum disease can directly increase the risk of heart disease, heart attack, diabetes, dementia, rheumatoid arthritis and even stroke. Women with poor dental health have also shown higher rates of preterm and low-birth-weight children. To prevent these health issues, practicing good oral hygiene is very important. People at an early age should get into good practices. Regular dental visits, brushing regularly, flossing and watching what they eat are all important steps in preventing dental diseases and keeping them in good health.

\section{Introduction}

Oral health: Oral health is multifaceted and includes the ability to speak, smile, smell, taste, touch, chew, swallow, and convey a range of emotions through facial expressions with confidence and without pain, discomfort, and disease of the craniofacial complex [1].

\section{Oral Hygiene}

The practice of keeping the mouth and teeth clean to prevent dental problems, most commonly, dental cavities, gingivitis, periodontal (gum) diseases and bad breathe. There are also oral pathologic conditions in which good oral hygiene is required for healing and regeneration of the oral tissues. These conditions include gingivitis, periodontitis, and dental trauma, such as subluxation, oral cysts, and following wisdom tooth extraction [2].

A healthy mouth is one that is free of pain and infection, with no untreated tooth decay, and with pink gum tissues that do not bleed on brushing. The mouth should be moist, with no evidence of lumps, ulcers or unusual color on or under the tongue, cheeks or gums [3]. It is possible for bacteria that originate in the mouth (for example from decayed teeth or periodontitis patient) to get into the bloodstream and so to other parts of the body including the cardiovascular network where they can cause serious infections. There are reports of people with poor oral hygiene experiencing infections in the heart or in artificial joints [2]. There is a modest association between periodontal disease and atherosclerosis, heart attacks, and stroke [3]. When the bacteria from these infections are isolated, they have been found to be the same as those in decayed teeth and in gum disease. Further, there is strong evidence linking poor oral hygiene with older people getting aspiration pneumonia [4]. This is a life-threatening condition where bacteria and debris from the mouth enter the lungs to cause an infection. Good oral hygiene can significantly reduce the risk of aspiration pneumonia [5,6]. Older people who have diabetes need to follow strict oral hygiene as they are at increased risk of periodontal disease, which can upset their diabetic control [7].

\section{Oral Infections and Bacteremia}

Oral microorganisms and cytotoxic by-products associated with local infections can enter the blood- stream or lymphatic system and cause damage or potentiate an inappropriate immune response else- where in the body, (Figure 1). Dissemination of oral bacteria into the bloodstream (bacteremia) can occur after most invasive dental procedures, including tooth extractions, 
endodontic therapy, periodontal surgery, and scaling and root planning [8-10]. Even routine oral hygiene procedures such as daily tooth brushing, sub gingival irrigation, and flossing may cause bacteraemia. However, these distant infections have been seen more often in high-risk patients such as those who are immuno compromised [3].

\section{a. These pathways (acting independently or collectively)}

i. Direct bacterial effects bacteraemia, (Figure 2).

ii. Autoimmune responses to the oral microbial toxins.

iii. Invasion and/or uptake of bacteria in endothelial cells and macrophages.

iv. Endocrine-like effects of pro-inflammatory mediators $[11,12]$. include

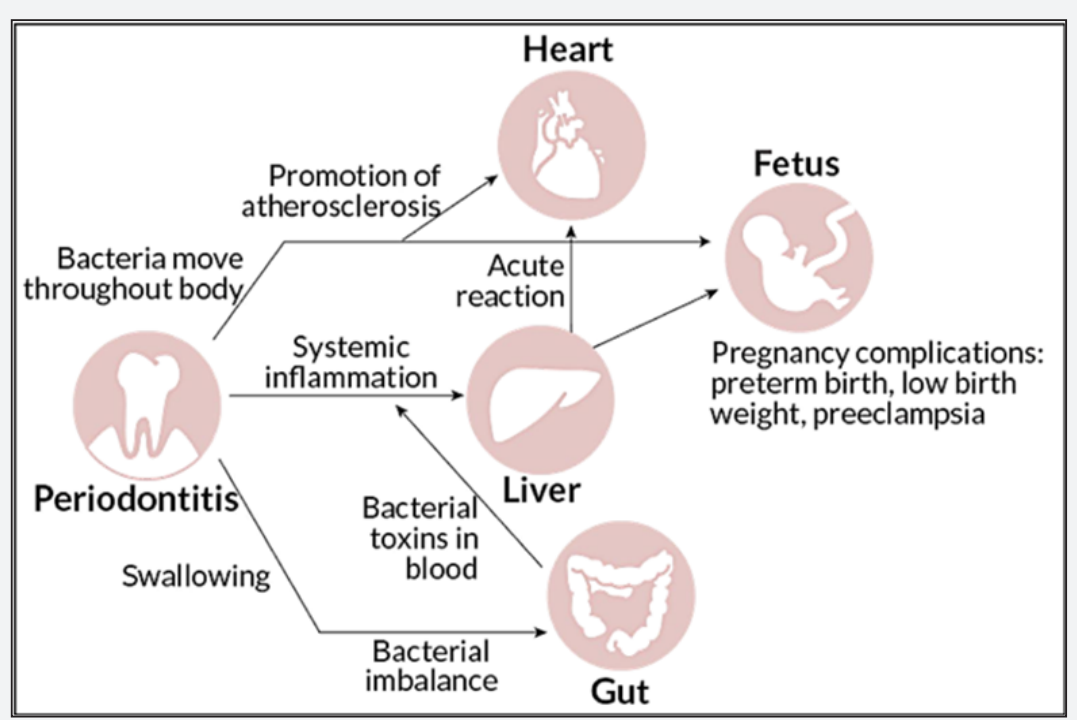

Figure 1: Dissemination of oral bacteria into the bloodstream.

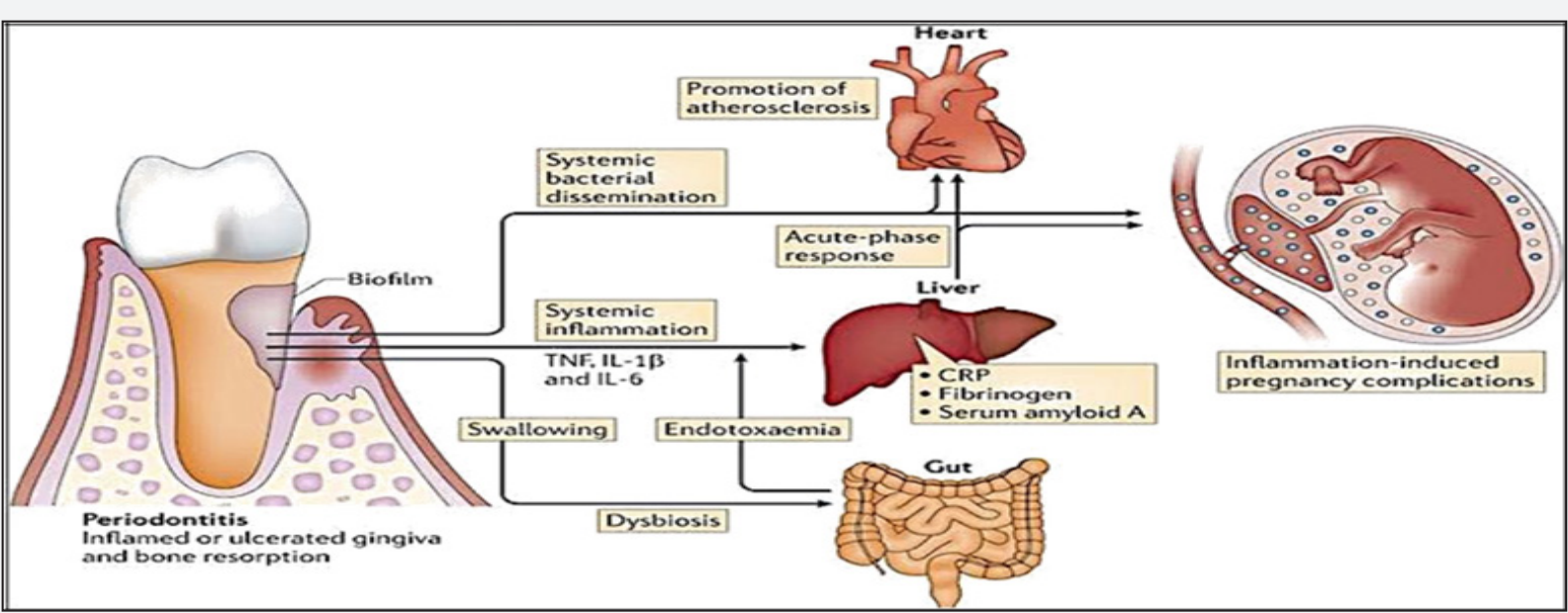

Figure 2 : Pathways of the distant infections.

Coronary heart disease: Atherosclerosis, Myocardial infarction, Infective Endocarditis, and Stroke

Endocarditis is caused by bacteria that adhere to damaged or otherwise receptive surfaces of the tissue that lines heart valves (the endocardium) [13]. Oral bacteria such as Streptococcus sanguis and Porphyromonas gingivalis induce platelet aggregation, associated with protein on their surface which leads to thrombus formation [3]. P. gingivalis, have demonstrated the ability to interact with the endothelial surface and to induce smooth-cell proliferation, causing damage and impairing the vasomotor functionality of the endothelial cells [14].Bacterial adherence and colonization of the valve. Microbes may also stimulate expression of tissue factor, which would activate coagulation [2].Oral bacteria can affect the heart when they enter the blood stream, attaching to fatty plaques in the coronary arteries (heart blood vessels) and contributing to clot 
formation $[15,16]$. Cells of the blood vessel wall and white blood cells and platelets can release prostaglandins(especially PGE2), interleukins (especially IL-1), thromboxane B2 (TBX2), and tumor necrosis factor alpha (TNF- $\alpha$ ).

Bacterial products in the blood may also stimulate liver production of other pro-inflammatory or pro-coagulant molecules such as C-reactive protein and fibrinogen [17]. LPS up regulates expression of endothelial cell adhesion molecules and secretion of interleukin-1 (IL-1), tumor necrosis factor alpha (TNF- $\alpha$ ), and thromboxane, which results in platelet aggregation and adhesion, formation of lipid-laden foam cells, and deposits of cholesterol and cholesterol esters. Cholesterol ester crystals, lipid-laden foam cells, and surface plasma proteins, including fibrin and fibrinogen [18]. During the process of coagulation, platelets would become trapped in the growing clot or thrombus. Microthrom bus formation is one of the key factors in the development of atherosclerotic plaques. As atherosclerotic plaques enlarge, the lumen of the coronary blood vessels narrows and the blood supply to the heart muscle becomes reduced atherosclerosis and affect blood coagulation [11].

Carotid artery intima media wall thickness (IMT): Cardiovascular disease generally refers to conditions that involve narrowed or blocked blood vessels that can lead to a heart attack, chest pain (angina), or stroke.14v Studies have shown that treatment of periodontal disease was associated with a decrease in markers of inflammation: CRP, IL-6. Prevention of infective endocarditis from oral bacteria depends on limiting the entry and dissemination of bacteria through the bloodstream and lymphatic circulation [17].

\section{Pneumonia}

Poor oral hygiene increases risk of pneumonia [4]. Bacteria that grow in the oral cavity can be aspirated into the lung to cause respiratory diseases such as pneumonia, especially in people with periodontal disease [12]. In severe aspiration pneumonia, $20 \%$ of organisms implicated are anaerobic and $80 \%$ aerobic. A acinomycetemcomitans, $\mathrm{P}$ gingivalis, Fusobacterium species, Capnocytophaga spp. P intermedia aspirated into the lower airways and cause pneumonia [6].

\section{Preterm Delivery and Low Birth-Weight}

Bacteria-induced activation of cell-mediated immunity leading to cytokine production and the synthesis and release of prostaglandins, growth factors, cytokines, interleukin-1 (IL- 1), interleukin-6 (IL-6), and tumor necrosis factor alpha (TNF- $\alpha$ ), matrix metalloproteinase have been found in the amniotic fluid of patients in preterm labor with amniotic fluid infection and other potent cytokines, which may directly or indirectly interfere with premature rupture of membranes or fetal growth and delivery [13]. Oral pathogens release toxins that reach the human placenta via the mother's blood circulation and interfere with fetal, also prompt accelerated production of inflammatory mediators PGE2 and TNF that normally build to a threshold level throughout pregnancy, and then cue the onset of labor, growth and development [15].

The biological mechanisms involve bacterially induced activation of cell-mediated immunity leading to cytokine production and the ensuing synthesis and release of $\mathrm{PG}$, which appears to trigger preterm labor. 16 Elevated levels of cytokines (IL-1, IL-6, and TNF- $\alpha$ ) have been found in the amniotic fluid of patients in preterm labor with amniotic fluid infection. These cytokines are all potent inducers of both $\mathrm{PG}$ synthesis and labor. Intra-amnionic levels of PGE2 and TNF- $\alpha$ rise steadily throughout pregnancy until a critical threshold is reached to induce labor, cervical dilation, and delivery. The elevated levels of these inflammatory mediators trigger premature delivery [19].

\section{Diabetes Mellitus}

The chronic release of tumor necrosis factor alpha (TNF- $\alpha$ ) and other cytokines such as those associated with periodontitis interferes with the action of insulin and leads to metabolic alterations.7 LPS and products of periodontopathic organisms may amplify the magnitude of the advanced glycation end product (AGE)-mediated cytokine response that is operative in diabetes mellitus.8 Periodontal infection challenge to these primed phagocytic cells may, in turn, amplify the magnitude of the macrophage response to AGE-protein, enhancing cytokine production and oxidative stress.9 Simultaneously, periodontal infection may induce a chronic state of insulin resistance, contributing to the cycle of hyperglycemia, nonenzymatic irreversibleglycation, and AGE-protein binding and accumulation, amplifying the classical pathway of diabetic connective tissue degradation, destruction, and proliferation [20]. Hence, the relationship between diabetes mellitus and periodontal disease or infection becomes two ways. A self-feeding two-way system of catabolic response and tissue destruction ensues, resulting in more severe periodontal disease and increased difficulty in controlling blood sugar [7].

\section{Periodontal disease and osteoporosis}

The underlying mechanism of increased bone resorption may be directed by increased systemic/local osteoclastic activity, or by local cellular or cytokine effects [5]. T and B-lymphocytes may also participate in osteoclast formation, either by expressing RANKL or by serving as osteoclast progenitor cells themselves. Exposure to periodontal infection may trigger RANKL activation and subsequent osteoclast activation and activity, inducing osteoporosis in patients with periodontal infection. Cytokines, such as IL-1 $\beta$, TNF- $\alpha$, IL-6, and IL-8 in concentrations capable of inducing bone resorption.10 Estrogen, either directly or indirectly, modulates cytokines that are important regulators of bone metabolism and also regulators of the host inflammatory response [21]. Osteoporosis may lead to tooth loss because the density of the bone that supports the teeth may be decreased [5]. 


\section{Renal Insufficiency}

Periodontal disease were associated with elevated serum creatinine level and initial and severe periodontitis were associated with Glomerular Filtration Rate GFR<60 ml/min [22]. Chronic renal disease can have significant effects on periodontal health including gingival hyperplasia in renal transplant patients receiving calcineurin inhibitors and calcium channel blockers. In addition, most epidemiologic studies have reported increased levels of plaque, calculus and gingival inflammation in ESRD populations. Whether an increased prevalence and severity of periodontitis exist in ESRD populations remains controversial. However, in view of the high rate of mortality from atherosclerotic complications, the strong association between increased inflammatory burden and atherosclerotic complications, and the possible contribution to systemic inflammation from periodontitis, the periodontal status of all chronic renal disease patients needs be carefully monitored [23].

\section{Oral-Health-Related Quality Of Life Dimensions}

Multiple factors act and interact in determining one's quality of life, as Wilson and Cleary (1995) and others have observed. Thus the idea of assessing quality of life along multiple "dimensions" implies a departure from a simple linear scale with excellent quality of life at one end and greatly diminished quality of life at the other, (Figure 3). The following sections explore several dimensions, beginning with effects along functional and psychosocial dimensions and concluding with a discussion of economic effects on quality of life [24].

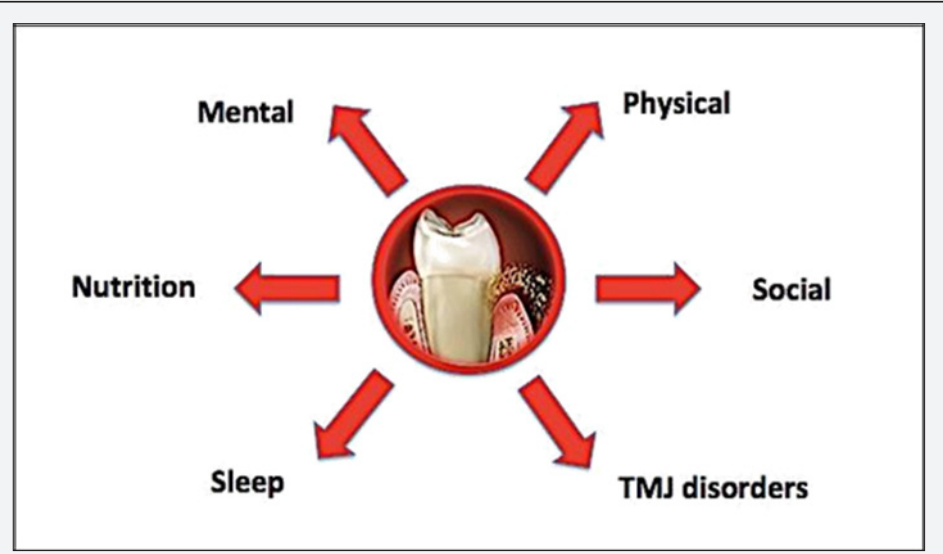

Figure 3 : Oral health related quality of life dimensions.

\section{Eating and chewing}

a. Missing teeth are qualitatively linked to a soft diet.

b. More Plaque deposit.

c. Patients who are edentulous (full or partial) favour diets higher in carbohydrates and lower in protein content.

d. Oral dysfunction can seriously impact nutritional status.

e. Maintaining muscle mass.

f. Chewing ability declines as tooth loss increases, regardless of denture replacement [25].

Ability to bite, chew, and swallow foods; limitations in food selection; and malnutrition. The type of high-fat foods that are recognized as risk factors for cardiovascular disease. Elevation of serum low-density lipoprotein has been shown to up regulate monocytic responses to LPS. Weight loss, which may affect overall health [26].

\section{TMJ disorders}

Temporomandibular disorders also reported problems with eating, talking, or swallowing. These conditions are often associated with limited mouth opening and severe pain [27]. Oral-facial pain, as a symptom of untreated dental or oral problems, associated with sleep deprivation, depression, and multiple adverse psychosocial outcomes [28].

\section{Sleep Issues}

3 to $5 \%$ percent of the population reported trouble sleeping because of pain or discomfort from dental problems [27]. Sleep problems associated with oral conditions appear to be most closely related to chronic pain, either directly or indirectly in cases where pain and insomnia are exacerbated by depression [28]. Sleep disturbance among persons with jaw pain increased with the severity of the pain [29].

\section{Psychosocial Dimensions}

The psychological and social dimensions of well-being and quality of life are deeply intertwined in everyday life [30].

a. Avoidance of social contact due to facial appearance.

b. Depressive effects of persistent oral pain.

Anxiety, depression and social stigma; these in turn may limit educational, career, and marital opportunities and affect other social relations [31]. 


\section{Conclusion}

Periodontal disease may affect the host's susceptibility to systemic disease through sub gingival bio films acting as reservoirs of Gram-negative bacteria, transient bacteraemia, release of microbial toxins, and as a reservoir of inflammatory mediators.

\section{References}

1. (2016) FDI's definition of oral health, Throat and Neck Medical Conditions: 12-23.

2. Barco CT (1991) Prevention of infective endocarditis: a review of the medical and dental literature. J Periodontol 62(8): 510-523.

3. Bayliss R, Clarke C, Oakley CM, Somerville W, Whitfield AG, et al. (1983) The microbiology and pathogenesis of infective endocarditis. Br Heart J 50(6): 513-519.

4. Zijlstra EE, Swart GR, Godfroy FJ, Degener JE (1992) Pericarditis, pneumonia and brain abscess due to a combined ActinomycesActinobacillus actino- mycetemcomitans infection. J Infect 25(1): 8387.

5. Mohajery M, Brooks SL (1992) Oral radiographs in the detection of early signs of osteoporosis. Oral Surg Oral Med Oral Pathol 73(1): 112117

6. Morris JF, Sewell DL (1994) Necrotizing pneumonia caused by mixed infection with Actinobacillus actinomycetem- comitans and Actinomyces israelii: case report and review. Clin Infect Dis 18(3): 450-452.

7. Hove KA, Stallard RE (1970) Diabetes and the periodontal patient. J Periodontol 41(12): 713-718.

8. Tervonen T, Karjalainen K (1997) Periodontal disease related to diabetic status A pilot study of the response to periodontal therapy in type 1 diabetes. J Clin Periodontol 24(7): 505-510.

9. Westfelt E, Rylander H, Blohme G, Jonasson P, Lindhe J (1996) The effect of periodontal therapy in diabetics Results after 5 years. J Clin Periodontol 23(2): 92-100.

10. Wowern N, Klausen B, Kollerup G (1994) Osteoporosis: a risk factor in periodontal disease. J Periodontol 65(12): 1134-1138.

11. Herzberg MC, Meyer MW (1998) Dental plaque, platelets, and cardiovascular diseases. Ann Periodontol 3(1): 151-160.

12. Goteiner D, Sonis ST, Fasciano R (1982) Cavernous sinus thrombosis and brain abscess initiated and main- tained by periodontally involved teeth. J Oral Med 37: 80-83.

13. Gibbs RS, Romero R, Hillier SL, Eschenbach DA, Sweet RL (1992) A review of premature birth and subclinical infection. Am J Obstet Gynecol 166(5): 1515-1528.
14. Genco RJ (1998) Periodontal disease and risk for myocardial infarction and cardiovascular disease. Cardiovasc Rev Rep 19(3): 34-40.

15. Dasanayake AP (1998) Poor periodontal health of the pregnant woman as a risk factor for low birth weight. Ann Periodontal 3: 206-212.

16. Davenport ES, Williams CE, Sterne JA, Sivapathasundram V, Fearne JM, et al. (1998) The East London study of maternal chronic periodontal disease and preterm low birth weight infants: study design and prevalence data. Ann Periodontol 3: 213-221.

17. DeStefano F, Anda RF, Kahn HS, Williamson DF, Russell CM (1993) Dental disease and risk of coronary heart disease and mortality. BMJ 306(6879): 688-691.

18. Geraci JE, Wilson JR (1982) Symposium on infective endocarditis III, Endocarditis due to gram-negative bacteria. Report of 56 cases. Mayo Clin Proc 57(3): 145-148.

19. McCormick MC (1985) The contribution of low birth weight to infant mortality and childhood morbidity. N Engl J Med 312(2): 82-90.

20. Harrison R, Bowen WH (1987) Periodontal health, dental caries, and metabolic control in insulin-dependent diabetic children and adolescents. Pediatr Dent 9(4): 283-286.

21. Kribbs PJ, Chesnut CH $3^{\text {rd }}$ (1984) Osteoporosis and dental osteopenia in the elderly. Gerodontology 3(2): 101-106.

22. Duran I, Erdemir EO (2004) Periodontal treatment needs of patients with renal disease receiving haemodialysis. Int Dent J 54: 274-278.

23. Craig RG (2008) Interactions between chronic renal disease and periodontal disease 14(1): 1-7.

24. Wilson IB, Cleary PD (1995) Linking clinical variables with healthrelated quality of life, A conceptual model of patient outcomes. JAMA 273(1): 59-65.

25. Ship JA, Duffy V, Jones JA, Langmore S (1996) Geriatric oral health and its impact on eating. J Am Geriatr Soc 44(4): 456-464.

26. Chauncey HH, Muench ME, Kapur KK, Wayler AH (1984) The effect of the loss of teeth on diet and nutrition. Int Dent J 34(2): 98-104.

27. Locker D, Grushka M (1987) The impact of dental and facial pain. J Dent Res 66(9): 1414-1417.

28. GouletJP, Lavigne GJ, Lund JP (1995) Jaw pain prevalence among Frenchspeaking Canadians and related symptoms of temporomandibular disorders. J Dent Res 74(11): 1738-1744.

29. Von Korff M, Ormel J, Keefe FJ, Dworkin SF (1992) Grading the severity of chronic pain. Pain 50(2): 133-149.

30. Beck AT (1967) Depression: clinical, experimental, and theoretical aspects. New York: Hoeber, USA.

31. Derogatis LR (1983) Symptom Checklist-90. Administration, scoring and procedures manual for the revised version. Baltimore: Clinical Psychometric Research, USA. 
(C) This work is licensed under Creative

BY DOI: $10.19080 / G J O .2018 .14 .555878$

\section{Your next submission with Juniper Publishers will reach you the below assets}

- Quality Editorial service

- Swift Peer Review

- Reprints availability

- E-prints Service

- Manuscript Podcast for convenient understanding

- Global attainment for your research

- Manuscript accessibility in different formats

( Pdf, E-pub, Full Text, Audio)

- Unceasing customer service

Track the below URL for one-step submission https://juniperpublishers.com/online-submission.php 